\title{
4. Incommensurability in design science: which comes first-theory or artefact?
}

\author{
MICHAEL DAVERN \\ ALISON PARKES \\ UNIVERSITY OF MELBOURNE
}

\section{Abstract}

There has been much debate and discussion in recent literature about the nature of information systems (IS) theory, the role of theory in design and the notions of design science and design theory. A central idea in much of this literature is the interplay between traditional theory-based research and the development of design theory through the building of information systems artefacts. In this chapter, we describe our recent experiences in the development of an artefact (a rule-based expert system called DG-In) based on a behavioural theory and the challenges we found as we attempted to reconcile it with relevant design theory. The potential for incommensurability in the research cycle between theory and artefact has significant implications for IS research - from both a design-science perspective and a behavioural-science perspective. It brings into question core ideas such as the development of a cumulative research tradition and notions of theory-based design and design theory more generally.

\section{Introduction}

The objective of design science is to create artefacts (broadly defined, including processes and methodologies) that are useful (Hevner et al. 2004). Design science, however, is more than building something useful. Good design science 'is the synergy between relevance and rigor' (Hevner 2007:91). Good design science should thus draw on the existing knowledge base of theories, frameworks and the like (see Hevner et al. 2004) and it must also contribute back to that 
knowledge base. It is in this regard that design science is more than simply good engineering. Iivari (2007) and Hevner (2007) are both quick to note, however, that good design science can be overly constrained creatively if it must be grounded only in theory. Rather a mix of sources (both theory and artefact) is preferred. Indeed, the mark of good design science lies in its rigorous evaluation of the artefacts developed (Iivari 2007; March and Smith 1995) and in its clear contribution to the 'knowledge base' (Hevner et al. 2004).

These premises for design science in the creative process (Hevner 2007) of design do, however, beg the question: which comes first - theory or artefact?

It is not our contention that either is more 'privileged' but rather, as we seek to demonstrate in this chapter, the difference in order can be non-trivial for the continuing development of theory, the advancement of artefact design and more broadly for the development of a cumulative research tradition (the 'knowledge base' in Hevner et al's [2004] terms).

The structure of the remainder of the chapter is as follows. In section two, we clarify our use of the terms 'theory' and 'artefact' and describe the cyclical relationship between the two. Using a context of explanation facilities and decisional guidance in intelligent systems, in section three, we contrast the artefact with theory and theory with artefact approaches. In section four, we document the relevant aspects of the artefact development that reveal to us the challenges and conflicts between the two approaches. We then describe the resulting incommensurability we observe in section five, and conclude in section six with the implications and questions for the future that are raised by the potential for incommensurability in IS research.

\section{Cycles and theories}

In practice, design science progresses not simply from theory to artefact or from artefact to theory, but cycles between the two (Hevner 2007; Hevner et al. 2004). In this cycle, theory can provide design guidance (prescriptions) and the artefact can inform theory. As Hevner et al. (2004:80) note, 'An artifact may have utility because of some as yet undiscovered truth', where truth is seen as the goal of behavioural science and utility is the goal of design science.

Theory and artefact are inseparable, as truth and utility are inseparable (Hevner et al. 2004). Indeed, drawing on Walls et al.'s (1992) concept of 'kernel theories' (theories from the natural and social sciences that inform design), Iivari (2007) claims that such kernel theories are a 'defining characteristic' of a 'design theory'. Consider Gregor's (2006) taxonomy of theories in IS. Gregor's taxonomy comprises five types - most notably: Type IV, explanation and prediction, 
and Type V, design and action. Type IV is found to be the most common in IS research and sits squarely in the domain of the natural and social sciences. It is the common notion of a theory. Type $\mathrm{V}$ theories prescribe how to do 'something' - providing, for example, a justified approach to developing an IS artefact. Notably, both Type IV and Type V theories are mutually interrelated; they inform each other. Artefact (an instantiation of a Type $V$ theory) informs theory (Type IV) and theory informs artefact. For simplicity, we use the generic term 'Theory' to refer to a Type IV theory and the generic term 'Artefact' to refer to a Type $\mathrm{V}$ theory as it is instantiated in a design creation. ${ }^{1}$

The theory-to-artefact or artefact-to-theory issue in IS is paradigmatic. Both perspectives recognise the importance of the other-for example, from the design-science side Gregor (2006; Gregor and Jones 2007) emphasises the importance of theory, whereas Orlikowski and Iacono (2001), from the 'theory' side, emphasise the centrality of the IT artefact. If, however, we take as a premise that these are different paradigms for research then by definition they will be incommensurable (Kuhn 1970). Thus, it is not simply an issue of which comes first - theory or artefact - but rather from which direction one is coming at any particular stage in the cycle between theory and artefact. Despite efforts to make the IT artefact more central in theory-driven research-and comparable efforts to build a 'design theory' from artefacts - the potential for incommensurability exists. It is this incommensurability that we seek to exemplify in this chapter. Importantly, our goal here is not to render the two incompatible, but rather through exposing the challenges of incommensurability we seek to enhance the quality of the exchange between these two world views. Initially, we focus our discussion on the broad distinction between Theory and Artefact; subsequently, we delve into the components of a design theory as articulated by Gregor and Jones (2007) to formalise our analysis of incommensurability.

\section{Directions matter: artefact to theory and theory to artefact}

Our perspective on the issue of incommensurability arose in the context of a program of research in decision support systems. The program of research was inspired by an artefact - an expert system called INSOLVE (Arnold et al. 2004a) - and research on the concept of decisional guidance (Silver 1988, 1990, 1991). The program of research entailed the development of a new artefact, (DG-

1 Notwithstanding there could be some debate about our use of these labels, and by no means do we seek to imply that either has a more privileged status in scientific endeavour. 
In), ${ }^{2}$ to test a behavioural theory about improving reliance on decision support systems through the provision of decisional guidance. Thus, at the outset, our research offered the potential to be informed by elements of artefact and elements of theory. Originally, we thought this would be a strength, but we had not anticipated the potential for incommensurability around central concepts and design features. Although we did not initially realise it, we were being driven more by theory than by artefact.

Critical to our behavioural theory was the concept of decisional guidance. Decisional guidance is defined as 'how a decision support system enlightens or sways its users' (Silver 1991). Decisional guidance has been operationalised in a number of ways, including manipulating data display formats (Wilson and Zigurs 1999), providing differing types of explanations (Limayem and Desanctis 2000), prompting decision makers to consider causally related information cues (Montazemi et al. 1996), providing feedback on decision accuracy (Montazemi et al. 1996) and providing information relating to available decision models (Parikh et al. 2001).

Two important issues are immediately evident here. First, we see that theoretical concepts such as decisional guidance can underdetermine design, as evidenced by the sizeable diversity of ways in which it has been operationalised. This is an issue we will return to when we reflect more broadly on matters of incommensurability. Second, and more specifically, in the context of expert systems, explanation facilities appear to be one form of the broader concept of decisional guidance (Limayem and Desanctis 2000). This suggests mapping is possible between the two concepts. To explore this mapping, we looked at established taxonomies of explanation facilities and decisional guidance.

\section{An artefact-based taxonomy of explanation facilities}

Gregor and Benbasat (1999) provide a review of research pertaining to explanation facilities in expert systems and present a taxonomy of explanation types. Notably, the research from which the taxonomy is derived is largely without 'theory'. Specifically, Gregor and Benbasat (1999:500) identify two streams of research-'design' and 'empirical': the former has 'few or no theoretical bases' and the latter employs 'designs mostly based on considered

\footnotetext{
2 DG-In (pronounced 'dig in') is a completely new and independent artefact from INSOLVE. Substantively, its commonality with INSOLVE lies only in the domain of application (insolvency decision making) and in the use of a common model of insolvency practitioner decision making (gathered through knowledge acquisition processes in the development of INSOLVE). There is no common code; indeed, the platforms are entirely different, as DG-In is web based.
} 
opinion and wisdom, rather than on the basis of theory'. The taxonomy is thus largely, in present language, artefact based (that is, the taxonomy is essentially a Type $\mathrm{V}$ theory).

The taxonomy proposed by Gregor and Benbasat (1999) comprises four types of explanation facilities

- trace or line of reasoning (which draws on data or rules to explain why decisions are or are not made)

- justification or support (which links back to underlying deep knowledge to justify the reasoning process)

- control or strategic (which explains the behaviour and/or decision strategy)

- terminological (which supplies definitional information).

The taxonomy is applied to a set of empirical papers to improve understanding of issues such as whether and why users need explanations, whether and how use of an explanation facility is beneficial and what type of explanations should be provided. It is a Type V Theory in Gregor's (2006) terms.

The existing INSOLVE artefact that partially inspired our work was an expert system that was specifically designed to provide explanations in a manner conformant with the Gregor and Benbasat (1999) taxonomy (see Arnold et al. 2004a for details). Indeed, Arnold et al. (2004a:6) specifically note that the design of the explanation facilities in INSOLVE are 'heavily grounded in the extant literature on optimal explanation facility design' and 'follow a theory synthesised by...Gregor and Benbasat (1999) to motivate our explanation types' (p. 9). Our 'Artefact' perspective was thus informed by the Gregor and Benbasat taxonomy - both in terms of the theory and in terms of its instantiation into INSOLVE. Mapping this taxonomy to the decisional guidance literature was thus an obvious requirement for advancing the development of our new artefact, DG-In.

\section{A theory-based taxonomy of decisional guidance}

While the roots of Gregor and Benbasat's explanation taxonomy were in artefacts, Silver's notion of decisional guidance was more about human behaviour. Indeed, Silver's (1990, 2008) own view is that understanding decisional guidance is about understanding a system as an agent of change. Unlike the Gregor and Benbasat taxonomy (a Type V theory), which seeks to say 'how to' design explanation facilities, Silver's development of decisional guidance is about 'the effects of system design features on the processes through which managers make decisions' (Silver 2008). Philosophically, decisional guidance would thus appear to be more rooted in the behavioural sciences (Silver's PhD 
is in decision sciences). While the decisional guidance taxonomy can inform design, it appears more commonly in literature grounded in theory (that is, Type IV theory) than artefact (Type $\mathrm{V}$ theory). It thus provides a contrasting perspective to the Gregor and Benbasat taxonomy. Nonetheless, it can and does inform design, although a design theory of decisional guidance has yet to fully emerge (not all the components of a design theory required by Gregor and Jones [2007] are yet present; see below for further discussion).

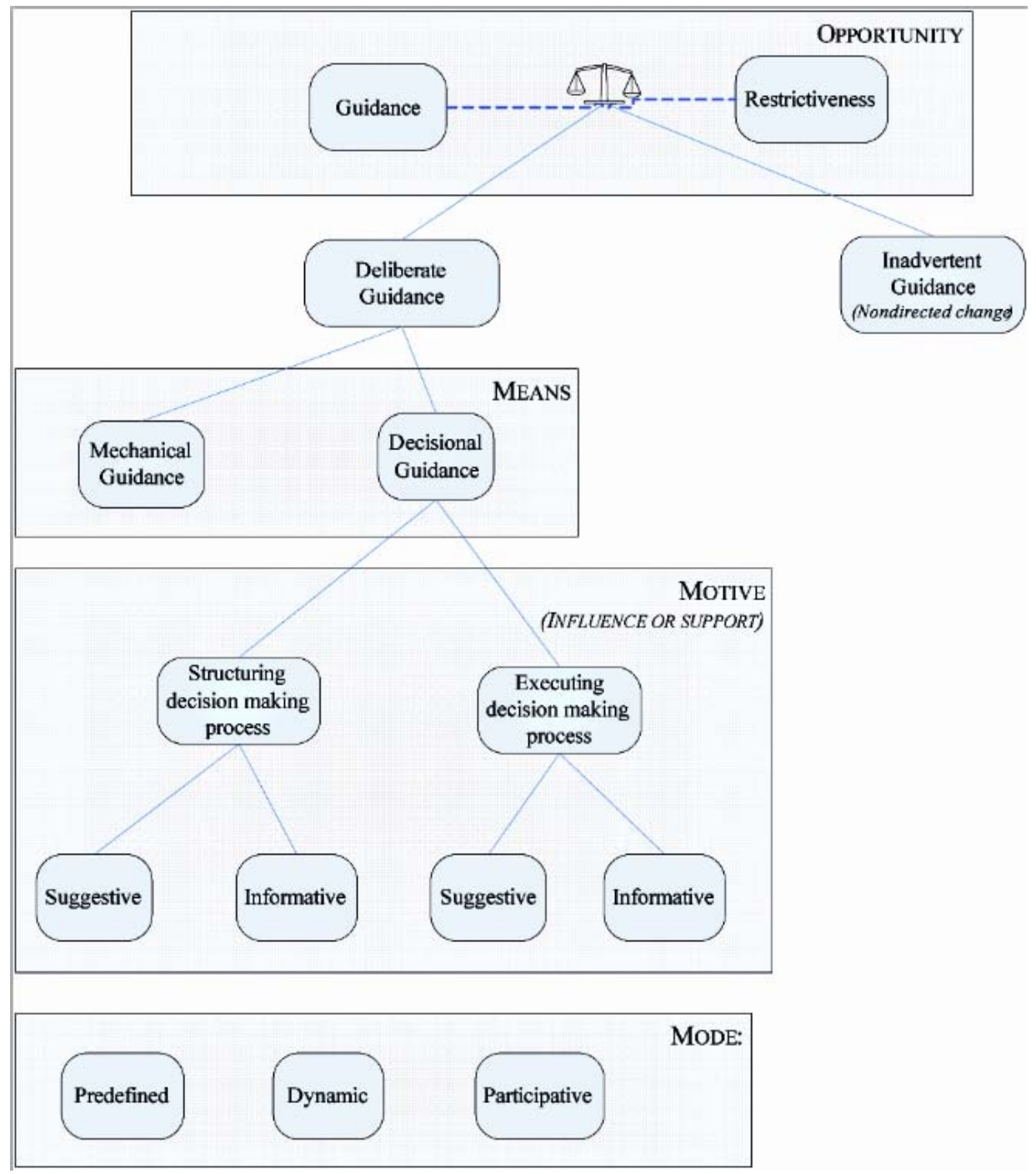

Figure 4.1 Decisional guidance overview

Adapted from Silver (1990:Figure 4, Forms of guidance) 
Decisional guidance can provide support for decision makers executing a given decision process in differing ways. Silver (1990) suggests that there is a choice to be made between suggestive guidance (swaying a decision maker by making recommendations) and informative guidance (enlightening decision makers by providing them with unbiased, pertinent information). A single decision aid can contain both forms of decisional guidance and either, or both, can be offered at any judgment point (Silver 1990). Empirically, it is unclear which of these forms of guidance is superior, particularly as existing empirical studies have not explicitly considered support for differing types of decision makers and decision tasks. Montazemi et al. (1996) find that informative guidance produces better decision outcomes when a task is complex, but a later study (Parikh et al. 2001) does not directly consider task complexity and finds that suggestive guidance produces better decision quality and user satisfaction in less time. It was these mixed findings that theoretically motivated our program of behavioural research that led to the development of DG-In.

Figure 4.1 synthesises decisional guidance concepts (Silver 1988, 1990, 1991) and visually depicts the taxonomy of decisional guidance. It is beyond the scope of the present work to fully describe this taxonomy. For the present purposes, our interests are primarily in the execution of decision processes and the role of informative versus suggestive guidance.

In seeking to develop and justify the design of the new DG-In, drawing primarily on the decisional guidance taxonomy, we were confronted with how it related to the taxonomy of explanations. It was here that the incommensurability became evident, so now we turn to a discussion of our development of DG-In.

\section{A theory-based artefact: the development of DG-In}

DG-In is a rule-based expert system purpose-built for a program of behavioural research about the effects of decisional guidance on user reliance on a knowledgebased system. DG-In supports users in an insolvency-based judgment task requiring a decision about the future of a company that has recently entered into voluntary administration. DG-In focuses on the initial impression that insolvency practitioners must form to decide at the outset whether to liquidate the distressed business or attempt to trade out of difficulty. It employs an underlying decision model and materials gathered in an extensive knowledge acquisition effort that led to the original INSOLVE system (Arnold et al. 2004a, 2004b; Collier et al. 1999; Leech et al. 1999), but in all other respects is an independent and distinct artefact. The decision model in DG-In has been 
independently validated by expert insolvency practitioners and employed in empirical research with practitioners - a majority of whom indicated they would find the tool useful in their practice.

For experimental purposes, several versions of DG-In were created, depending on the particular forms of decisional guidance that were desired. The underlying decision model was identical in all cases. Suggestive guidance was operationalised by leveraging the inherent hierarchical structure of the decision model. Specifically, where multiple underlying factors contributed to an interim judgment within the decision model, the opportunity existed to both ask users directly for the interim judgment and provide suggestive guidance as to the interim judgment. After extensive modelling exercises, an additive model was found to be the most effective way of generating the suggestive guidance. Figure 4.2 shows the relevant underlying factors and then the resulting suggestive guidance.

Example underlying factors: Question 3. Will the practitioner be paid?

3.1 Will there be sufficient funds to pay the practitioner's fees and continuing expenses?

3.2 Is a challenge to the practitioner's priority to receive payment of their fees and expenses unlikely?

\section{DG-In}

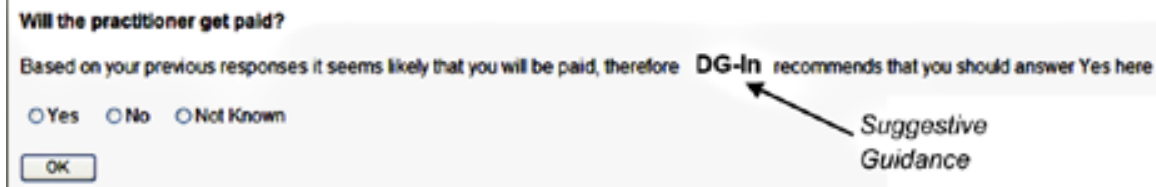

Figure 4.2 Suggestive guidance operationalisation

Informative guidance in the form of definitional text was also embedded into appropriate questions.

\section{DG-In}

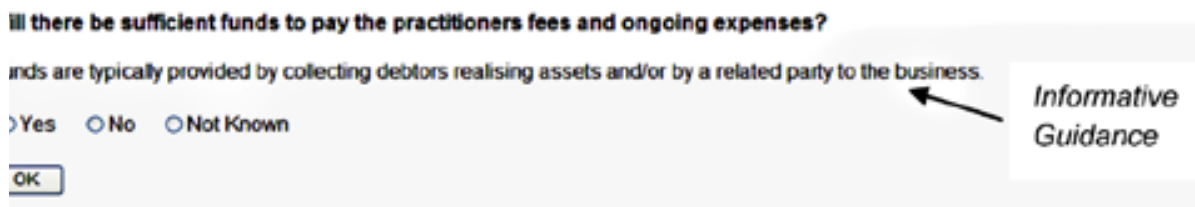

Figure 4.3 Example screenshot displaying informative guidance treatment 
As noted earlier, decisional guidance has been operationalised in many ways. Thus, there was some interpretation used here since the theoretical concept, as an abstraction, underdetermined the design. This design interpretation was guided by immersion in the decisional guidance literature, discussions with Silver (the originator of the concept) and a guiding principle of 'would Silver recognise this as the form of decisional guidance intended'. This principle became quite important in the face of pressure from colleagues to align the design more closely with the Gregor and Benbasat (1999) taxonomy.

\section{Demonstrating incommensurability}

\section{Mapping between the two taxonomies.}

Attempts to map from the two forms of decisional guidance (informative versus suggestive) to Gregor and Benbasat's (1999) four types of explanation (trace, justification, strategic, terminological) proved to be less than straightforward and were a source of much debate among the research team and colleagues more broadly. Interestingly, in consulting with colleagues during the development of DG-In there was substantial negative feedback about the decisional guidance concept from colleagues who had been involved in the development of the original INSOLVE artefact. Having developed INSOLVE with explanation facilities as per Gregor and Benbasat (1999), they repeatedly challenged us to reconcile the explanation facilities taxonomy with the decisional guidance taxonomy. Importantly, they did not reject the concepts and theory of decisional guidance; rather they wanted them reconciled with their artefact perspective.

As the above example of informative guidance suggests (see Figure 4.3), informative guidance mapped quite clearly to the terminological category in Gregor and Benbasat's taxonomy. Suggestive guidance, however, did not seem to fit easily with any of the other categories. This was perplexing in both directions. A priori, decisional guidance appeared to be a broader concept than explanation facilities, so we were surprised we could not map suggestive guidance to the other elements in the Gregor and Benbasat taxonomy, no matter from which direction we approached the issue.

When considering these possible mappings, we could see that suggestive guidance (recommending what to do) was somewhat similar to explaining a problem-solving strategy (a control or strategic explanation in Gregor and Benbasat's [1999] taxonomy). Providing a recommendation does not, however, necessarily involve explaining how that recommendation was arrived at, leading us to conclude that suggestive guidance is not synonymous with a control or strategic explanation. Similarly, providing a recommendation does 
not necessarily include explaining why that recommendation is being made (ruling out a mapping to trace or line of reasoning explanations)-nor is it necessary to justify why the action is being recommended (ruling out a mapping to justification or support explanations). The remaining explanation typeterminological - is clearly unlike suggestive guidance and in fact maps directly to informative guidance (providing additional unbiased information). Thus, despite our a priori expectations, the expectations of colleagues and indeed the premise of a cycle between theory and artefact, we found the two taxonomies to be largely incommensurable (importantly, both taxonomies have been presumed in the literature to be comprehensive).

\section{Comparing two theories or two artefacts}

To formalise our arguments regarding incommensurability, we turn to Gregor and Jones's (2007) specification of the components of a 'Design Theory'. More specifically, we seek to compare the design theory specified by Gregor and Benbasat (1999) with a design theory based on the decisional guidance literature. Gregor and Jones identify eight components to a design theory: purpose and scope; constructs; principles of form and function; artefact mutability; testable propositions; justificatory knowledge; principles of implementation; and expository instantiation. Notably, the current decisional guidance literature does not yet adequately address all eight components of a design theoryreflecting its origins as a Type IV theory rather than a Type V theory. Table 4.1 details exemplars in Gregor and Benbasat (1999) of each of the eight components of a design theory. In Table 4.1, we also present potential exemplars of a design theory for decisional guidance derived from prior literature.

\section{Table 4.1 Design theory components for explanations and decisional} guidance

\begin{tabular}{|l|l|l|}
\hline \multicolumn{1}{|l}{ Type } & \multicolumn{1}{l|}{$\begin{array}{l}\text { Exemplars in Gregor and Benbasat } \\
\text { (1999) }\end{array}$} & \multicolumn{1}{|c|}{$\begin{array}{l}\text { A 'design theory' for } \\
\text { decisional guidance }\end{array}$} \\
\hline $\begin{array}{l}\text { Purpose and scope } \\
\text { Goals and boundaries } \\
\text { of the artefact/design } \\
\text { theory }\end{array}$ & $\begin{array}{l}\text { To present a unifying framework that } \\
\text { integrates existing empirical work on } \\
\text { explanations on intelligent systems. } \\
\text { To improve performance and learning } \\
\text { and improve user perceptions of } \\
\text { intelligent systems. In essence, to } \\
\text { guide design choices to achieve more } \\
\text { effective and appropriate explanation } \\
\text { facilities. }\end{array}$ & $\begin{array}{l}\text { To build a knowledge } \\
\text { base to better } \\
\text { understand decisional } \\
\text { guidance and be able to } \\
\text { provide more effective } \\
\text { support for decision } \\
\text { makers. }\end{array}$ \\
\hline $\begin{array}{l}\text { Constructs } \\
\text { 'Entities of interest' }\end{array}$ & $\begin{array}{l}\text { Relevant examples: explanation types, } \\
\text { format, provision mechanism and } \\
\text { content; trace, justification or support, } \\
\text { control or strategic, terminological. }\end{array}$ & $\begin{array}{l}\text { Relevant examples: } \\
\text { inadvertent guidance, } \\
\text { deliberate guidance, } \\
\text { suggestive guidance, } \\
\text { informative guidance. }\end{array}$ \\
\hline
\end{tabular}




\begin{tabular}{|c|c|c|}
\hline $\begin{array}{l}\text { Principles of form and } \\
\text { function } \\
\text { Abstract plan of the } \\
\text { artefact }\end{array}$ & $\begin{array}{l}\text { Suitably designed explanations } \\
\text { improve performance, learning and } \\
\text { user perceptions of the system (per } \\
\text { Gregor and Benbasat 1999; Figure } \\
\text { 4.1). }\end{array}$ & $\begin{array}{l}\text { Deliberately (as opposed } \\
\text { to inadvertently) } \\
\text { incorporating guidance } \\
\text { in a system offers } \\
\text { potential for more } \\
\text { supportive systems. }\end{array}$ \\
\hline $\begin{array}{l}\text { Artefact mutability } \\
\text { Scope for change or } \\
\text { variability in artefact } \\
\text { design under the theory }\end{array}$ & $\begin{array}{l}\text { Explanations can be case/context } \\
\text { specific rather than generic. Reasoning } \\
\text { trace, justification and control } \\
\text { explanations are typically specific; } \\
\text { terminological explanations are usually } \\
\text { generic. }\end{array}$ & $\begin{array}{l}\text { Different guidance } \\
\text { mechanisms can } \\
\text { be instantiated in a } \\
\text { variety of ways and } \\
\text { the appropriate type of } \\
\text { guidance is dependent } \\
\text { on the nature of the } \\
\text { support that is required. }\end{array}$ \\
\hline $\begin{array}{l}\text { Testable propositions } \\
\text { Statements that can be } \\
\text { empirically tested }\end{array}$ & $\begin{array}{l}\text { See Propositions } 1-9 \text { in Gregor } \\
\text { and Benbasat (1999)-for } \\
\text { example: explanation use improves } \\
\text { performance; explanations that require } \\
\text { less effort will be more effective; } \\
\text { novices and experts use explanations } \\
\text { differently. }\end{array}$ & $\begin{array}{l}\text { Different types of } \\
\text { guidance influence } \\
\text { decision makers } \\
\text { differently. }\end{array}$ \\
\hline $\begin{array}{l}\text { Justificatory knowledge } \\
\text { 'Kernel theories' that } \\
\text { support the design }\end{array}$ & $\begin{array}{l}\text { Theories from cognitive psychology on } \\
\text { human reasoning, such as cognitive } \\
\text { learning theory and Toulmin's theory } \\
\text { of argumentation. }\end{array}$ & $\begin{array}{l}\text { Synthesises a broad } \\
\text { base of decision-making } \\
\text { judgment and choice } \\
\text { literatures and prior DSS } \\
\text { literature. }\end{array}$ \\
\hline $\begin{array}{l}\text { Principles of } \\
\text { implementation } \\
\text { Processes for } \\
\text { instantiating the theory } \\
\text { into an artefact in a } \\
\text { given context }\end{array}$ & $\begin{array}{l}\text { Explanations should be provided } \\
\text { 'automatically, if this can be done } \\
\text { relatively unobtrusively, or by } \\
\text { hypertext links' (Gregor and Benbasat } \\
\text { 1999:517). }\end{array}$ & $\begin{array}{l}\text { Decisional guidance has } \\
\text { been operationalised } \\
\text { in a variety of ways; } \\
\text { specific principles of } \\
\text { implementation are the } \\
\text { subject of continuing } \\
\text { empirical investigation. }\end{array}$ \\
\hline $\begin{array}{l}\text { Expository instantiation } \\
\text { An artefact that is a } \\
\text { physical and testable } \\
\text { manifestation of the } \\
\text { theory }\end{array}$ & INSOLVE & DG-In \\
\hline
\end{tabular}

Table 4.2 details on a component-by-component basis the differences between the design theory of Gregor and Benbasat (1999) and a design theory of decisional guidance based on our interpretation of the literature and as instantiated in DG-In. 
Table 4.2 Comparing 'design theories'

\begin{tabular}{|c|c|}
\hline Type & $\begin{array}{l}\text { Comparison between Gregor and Benbasat (1999) (G\&B) and a 'design } \\
\text { theory' for decisional guidance }\end{array}$ \\
\hline $\begin{array}{l}\text { Purpose and } \\
\text { scope }\end{array}$ & $\begin{array}{l}\text { G\&B's 'classification of explanations... reflects...the historical } \\
\text { development of explanation facilities'. It seeks to integrate prior artefact- } \\
\text { based research. In contrast, the decisional guidance taxonomy was } \\
\text { established as theory to guide DSS research into the future. }\end{array}$ \\
\hline Constructs & $\begin{array}{l}\text { G\&B describe components and types of explanations based on } \\
\text { observations from artefacts and theories. The decisional guidance } \\
\text { literature starts from theory and provides a taxonomy centred on the } \\
\text { intentions of the designer and the nature of support intended. }\end{array}$ \\
\hline $\begin{array}{l}\text { Principles } \\
\text { of form and } \\
\text { function }\end{array}$ & $\begin{array}{l}\text { While there are some overlaps here, G\&B emphasise that better design } \\
\text { results in better outcomes, whereas Silver emphasises that better designs } \\
\text { provide more support for users. Both consider process and outcomes, but } \\
\text { the emphasis is different (reflecting their intellectual heritage and stage } \\
\text { of development). }\end{array}$ \\
\hline $\begin{array}{l}\text { Artefact } \\
\text { mutability }\end{array}$ & $\begin{array}{l}\text { Both G\&B's and Silver's decisional guidance concepts allow for variability } \\
\text { in contextualising or instantiating constructs. Notably, this variability only } \\
\text { enhances the potential for incommensurability. }\end{array}$ \\
\hline $\begin{array}{l}\text { Testable } \\
\text { propositions }\end{array}$ & $\begin{array}{l}\text { G\&B are able to be much more specific about design-relevant testable } \\
\text { propositions as they synthesise and taxonomise existing artefact-based } \\
\text { research. In contrast, the testable propositions evident in the decisional } \\
\text { guidance literature reflect the potential variability for instantiating } \\
\text { abstract concepts into design implementations. }\end{array}$ \\
\hline $\begin{array}{l}\text { Justificatory } \\
\text { knowledge }\end{array}$ & $\begin{array}{l}\text { G\&B use existing theory to explain/justify the theory and taxonomy. In } \\
\text { contrast, the decisional guidance literature begins with existing theory } \\
\text { and creatively synthesises it to develop a taxonomy to guide designs that } \\
\text { post date the creation of the taxonomy. }\end{array}$ \\
\hline $\begin{array}{l}\text { Principles of } \\
\text { implementation }\end{array}$ & $\begin{array}{l}\text { While there have been several behavioural studies of decisional guidance, } \\
\text { principles of implementation have not yet coalesced. In contrast, the } \\
\text { G\&B taxonomy is heavily derived from artefacts so the principles of } \\
\text { implementation are more clearly established. }\end{array}$ \\
\hline $\begin{array}{l}\text { Expository } \\
\text { instantiation }\end{array}$ & INSOLVE versus DG-In \\
\hline
\end{tabular}

The analyses in Tables 4.1 and 4.2 provide some clues as to the source of incommensurability we observed. While there is a not insubstantial body of literature on decisional guidance it is still not adequate to specify fully all the necessary components of a design theory. The principles of implementation, in particular, are still open to interpretation. In short, the design of an artefact based on the theory and literature surrounding decisional guidance underspecifies the artefact; multiple interpretations are possible. Similarly, we see that Gregor and Benbasat (1999) use multiple theoretical perspectives as justificatory knowledge. It is thus difficult to connect the artefact elements described by Gregor and Benbasat's taxonomy to a single or unified coherent Type IV theory. The cycle between theory and artefact is problematic in both directions - the essence of incommensurability. 


\section{Reflections and implications of incommensurability}

One interpretation of our experience here is simply that we have two incompatible 'theories': decisional guidance and explanations. Yet both are intended to feed design through the iterative cycle between theory and artefact. This is obvious in Gregor and Benbasat's work, which constitutes a Type V theory. While Silver's (1988) original research is behavioural and comes from a Type IV theory background, Silver (2008) himself now describes his research focus as being on 'design'. The problem is thus much broader. It illustrates that despite the best of intentions (ours and, arguably, Silver's and Gregor and Benbasat's), the literature that develops from the theory (Type IV) side can result in designs incommensurable with the developments in the literature on the Artefact side (Type V). The conceptualisation (Gregor 2006; Hevner 2007; Hevner et al. 2004; Iivari 2007) of design feeding from both advances in design theory and more traditional theory-based research becomes a little more challenging to realise in practice.

Fundamentally, the concern is not whether we have incommensurable approaches or simply incompatible theories; rather the issue is: are our experiences of the challenges in the development of DG-In an outlier event or a common occurrence? We believe it to be the latter and that this presents a great challenge for design-science and behavioural-science researchers in IS. The underlying problem is that theory underdetermines design and artefact design can generalise to multiple theoretical abstractions. Theory as an abstraction underdetermines reality. The implication for design science-with no disrespect intended - is that you can potentially build multiple theories from an artefact. The implication for behavioural science is that a given theory can be instantiated into multiple different artefact designs (because of the lack of detailed implementation principles), with potentially different consequences.

At issue is whether, in terms of design principles, we have different levels of granularity - specifically, whether Type IV theories could be less design specific than Type $\mathrm{V}$ theories. Indeed, we would argue that in practice the distinction between Type IV and Type $\mathrm{V}$ becomes less of a dichotomy and more of a continuum of varying degrees of design specificity (or, to put it another way, the extent to which all the components of a design theory required by Gregor and Jones [2007] are present). Thus, we can face incommensurability in design and incommensurability in theory when we cycle between Type IV and Type V theories in the effort to advance design.

We recognise there could be debate about some of the issues we have observed, described and reflected on in this chapter. Our purpose has not been to make a definitive argument here, but rather to describe an experience that led us 
to ask some challenging - and currently largely unanswered - questions for IS research. In short, if there is a broader potential for incommensurability akin to what we have observed, we are left with several burning questions.

- What does it mean to conduct theory-driven/grounded design-science research?

- What does it mean when the two approaches to design agree theoretically (for example, as in our experiences with informative guidance)?

- Does this mean we have the theory right?

- Does this mean we have the design right?

- What does it mean when the two approaches to design are theoretically incommensurable (for example, as in our experiences with suggestive guidance)?

- Does this mean we do not yet have adequate theory?

- Does this mean we need to consider more carefully the difference in granularity of theories with respect to design specificity?

- How can the field at large meaningfully create a cumulative research tradition in IS with the IT artefact at the centre?

- What are the implications of incommensurability for how we evaluate research-both in the design-science tradition and in the behaviouralscience tradition?

At the very least, we hope we have sensitised the research community to the potential for incommensurability - a problem likely only to be exacerbated by the rapid technological advancement we face in IS and the relatively slow pace of progress in traditional theory-based research.

\section{References}

Arnold, V., Clark, N., Collier, P. A., Leech, S. A. and Sutton, S. G. 2004a, 'Explanation provision and use in an intelligent decision aid', International Journal of Intelligent Systems in Accounting, Finance \& Management, vol. 12, no. 1, pp. 5-28.

Arnold, V., Collier, P. A., Leech, S. A. and Sutton, S. G. 2004b, 'Impact of intelligent decision aids on experienced and novice decision-makers' judgments', Accounting \& Finance, vol. 44, no. 1, pp. 1-26.

Collier, P. A., Leech, S. A. and Clark, N. 1999, 'A validated expert system for decision making in corporate recovery', International Journal of Intelligent Systems in Accounting, Finance \& Management, vol. 8, pp. 75-88. 
Gregor, S. 2006, 'The nature of theory in information systems', MIS Quarterly, vol. 30, no. 3, pp. 611-42.

Gregor, S. and Benbasat, I. 1999, 'Explanations from intelligent systems: theoretical foundations and implications for practice', MIS Quarterly, vol. 23, no. 4, pp. 497-530.

Gregor, S. and Jones, D. 2007, 'The anatomy of a design theory', Journal of the Association for Information Systems, vol. 8, no. 5, pp. 312-35.

Hevner, A. R. 2007, 'A three cycle view of design science research', Scandinavian Journal of Information Systems, vol. 19, no. 2, pp. 87-92.

Hevner, A. R., March, S. T. and Park, J. 2004, 'Design science in information systems research', MIS Quarterly, vol. 28, no. 1, pp. 75-105.

Iivari, J. 2007, 'A paradigmatic analysis of information systems as a design science', Scandinavian Journal of Information Systems, vol. 19, no. 2, pp. 39-64.

Kuhn, T. 1970, The Structure of Scientific Revolutions, Second edition, University of Chicago Press, Ill.

Leech, S. A., Collier, P. A. and Clark, N. 1999, 'A generalized model of decisionmaking processes for companies in financial distress', Accounting Forum, vol. 23, no. 2, pp. 155-74.

Limayem, M. and Desanctis, G. 2000, 'Providing decisional guidance for multicriteria decision making in groups', Information Systems Research, vol. 11 , no. 4, pp. 386-401.

March, S. T. and Smith, G. F. 1995, 'Design and natural science research on information technology', Decision Support Systems, vol. 15, pp. 251-66.

Montazemi, A. R., Wang, F., Nainar, S. M. K. and Bart, C. K. 1996, 'On the effectiveness of decisional guidance', Decision Support Systems, vol. 19, pp. $181-98$.

Orlikowski, W. J. and Iacono, C. S. 2001, 'Desperately seeking the "IT" in IT research - a call to theorizing the IT artifact', Information Systems Research, vol. 12, no. 2, pp. 121-34.

Parikh, M., Fazlollahi, B. and Verma, S. 2001, 'The effectiveness of decisional guidance: an empirical evaluation', Decision Sciences, vol. 32, no. 2, pp. 30331. 
Silver, M. S. 1988, 'Descriptive analysis for computer-based decision support', Operations Research, vol. 36, no. 6, pp. 904-16.

Silver, M. S. 1990, 'Decision support systems: directed and nondirected change', Information Systems Research, vol. 1, no. 1, pp. 47-70.

Silver, M. S. 1991, 'Decisional guidance for computer-based decision support', MIS Quarterly, vol. 15, no. 1, pp. 105-22.

Silver, M. S. 2008, Fordham University web site, New York, <http://www.bnet. fordham.edu/public/ics/msilver/msilver.html>

Walls, J. G., Widmeyer, G. R. and El Sawy, O. A. 1992, 'Building an information systems design theory for vigilant EIS', Information Systems Research, vol. 3, no. 1, pp. 36-59.

Wilson, E. V. and Zigurs, I. 1999, 'Decisional guidance and end-user display choices', Accounting, Management \& Information Technology, vol. 9, pp. 4975. 